\title{
UNIDADE DIALÉTICA NO FAZER DOCENTE - AÇÃO E REFLEXÃO - REGISTROS NO ENSINO DE CIÊNCIAS NATURAIS
}

\section{DIALECTICAL UNITY IN MAKING FACULTY - ACTION AND REFLECTION -RECORDS IN THE TEACHING OF NATURAL SCIENCES}

\author{
1Valeria da Silva Lima e ${ }^{2}$ Maylta dos Anjos Brandão \\ ${ }^{1}$ Instituto Federal de Ciência, Tecnologia e Educação do Rio de Janeiro/ IFRJ/ PROPEC \\ 2 Instituto Federal de Ciência, Tecnologia e Educação do Rio de Janeiro/ IFRJ/ PROPEC
}

\section{RESUMO}

O Ensino de Ciências se constitui numa prioridade para os anos iniciais do Ensino Fundamental, na medida em que pode promover, a partir da mediação docente, conhecimentos e habilidades que contribuirão para a aquisição de conceitos científicos, formação da cidadania, análise crítica da realidade, permitindo escolhas e tomadas de decisão numa concepção dialética de mundo, onde os atores sociais produzem saberes. Diante disso, este artigo teve o objetivo de analisar e registrar orientações pedagógicas na primeira fase da Educação Básica, a fim de contribuir para a efetivação do Ensino de Ciências Naturais, tendo em vista uma experiência de campo, com observação participante, numa escola municipal de Barra Mansa. Tal pesquisa possibilitou, mediante o exercício da práxis pedagógica, ao trabalhar com conceitos da ciência utilizando como aporte a música e a poesia para a construção do pensamento científico, o olhar investigativo, a reflexão crítica da natureza, da vida, da sociedade e da tecnologia, para sujeitos alunos na tenra idade.

Palavras-chave: Práxis Pedagógica, Ensino de Ciências, Anos Iniciais do Ensino Fundamental

\begin{abstract}
ABSTRAT
The teaching of science is a priority for the initial years of basic education, to the extent that can promote, from the faculty mediation, knowledge and skills that will contribute to the acquisition of scientific concepts, training of citizenship, critical analysis of reality, allowing choices and decision-making in a dialectic of world, where social actors produce knowledges. In addition, this article aimed to analyze and record pedagogical guidelines in the first stage of basic education, in order to contribute to the realization of the teaching of natural sciences, with a view to field experience, with participant observation in a school hall of Barra Mansa Such research has made it possible, through the exercise of pedagogical praxis, when working with concepts of science using as a contribution to music and poetry for the construction of scientific thought, the look investigative, critical reflection of nature, of life, of society and of technology, to subject students at the tender age.
\end{abstract}

Keywords: Pedagogical Praxis, Science Education, Early Years of Elementary Education 


\section{INTRODUÇÃO}

O Ensino de Ciências Naturais nos anos iniciais é uma prioridade, pois a partir do conhecimento das Ciências muitos saberes poderão ser construídos para compreensão e entendimento do mundo, as transformações naturais e tecnológicas.

Embora tenhamos muitos desafios para ensinar determinados conteúdos e conceitos científicos da humanidade, é importante levarmos em conta, a formação e aperfeiçoamento docente e o compromisso com o exercício do pensar por meio de interações dialógicas entre professor e aluno nos anos iniciais.

Existem inúmeras possibilidades de Ensinar Ciências nos anos iniciais, de maneira que o conhecimento científico seja construído com significação, partindo do conhecimento do cotidiano, das concepções prévias dos alunos evoluindo do concreto para o abstrato.

A práxis é o exercício docente que envolve a atitude da ação e a reflexão numa unidade dialética do ensino, entendida como um pensar crítico sobre o contexto real educativo estabelecido, as condições de ensino, bem como o despertar consciente para a transformação.

Os sujeitos do processo educativo, precisam desempenhar suas funções específicas de ensino, os quais deverão promover o conhecimento ativo do mundo material, das transformações na natureza para o uso consciente das novas tecnologias, incluindo as mudanças no ensino.

Assim sendo, este artigo tem como objetivo registrar ações pedagógicas na primeira fase da Educação Básica, a partir de experiências de campo onde a observação e prática docente, possibilitou, mediante o exercício da práxis pedagógica, a construção do conhecimento crítico da natureza, da vida, da sociedade e da tecnologia.

Desta forma, falaremos das possibilidades apreendidas, observadas e praticadas no campo da pesquisa nos anos iniciais do Ensino Fundamental, a fim de contribuirmos com o ensino de Ciências Naturais, com a sabedoria do cotidiano, proporcionando construções para o saber científico, por meio de práticas dinâmicas e interativas.

Amparado na práxis freireana em que ação e a reflexão constroem uma unidade dialética no fazer docente, buscamos contribuir para que a concepção libertadora da educação defendida por Freire alcance as salas de aula a partir conhecimento crítico real. 
O campo da pesquisa foi uma escola municipal de Barra Mansa do Estado do Rio de Janeiro onde relataremos experiências realizadas na sala de aula nos anos iniciais na disciplina de Ciências Naturais em que a construção do conhecimento científico foi construída partir de práticas interativas entre professor e aluno, tendo em vista a formação da cidadania.

Nas linhas abaixo, abordaremos algumas possibilidades envolvendo a mediação docente para a práxis no ensino de Ciências Naturais nos primeiros anos, valorizando o papel docente como sujeito do conhecimento, as interações dialógicas com os alunos e professores e a utilização de estratégias que contribuíram para o ensino.

\section{A CONCEPÇÃO DA PRÁXIS EM FREIRE, UM CAMINHO PARA A CONSCIENTIZAÇÃO}

Paulo Freire propôs uma educação dialógica para o desenvolvimento consciente da realidade social, produzidos nas relações interativas e amorosas entre os homens, o amor é, também, diálogo, que como tarefa de sujeitos, não pode ser baseado em relação de dominação (FREIRE, 1987). Para o autor,

[...] homem dialógico, que é crítico, sabe que, se o poder de fazer, de criar, de transformar, é um poder dos homens, sabe também que podem eles, em situação, alienados, ter este poder prejudicado. Esta possibilidade, porém, em lugar de matar no homem dialógico a sua fé nos homens, aparece a ele, pelo contrário, pelo desafio ao qual tem de responder. Está convencido que este poder de fazer e transformar, mesmo que negado em situações concretas, tende a renascer. Pode renascer. Pode constituir-se. Não gratuitamente, mas na e pela luta por sua libertação (FREIRE, 1987, p. 81)

Educação dialógica em Freire é práxis, logo o encontro entre os homens para ser mais, não se dá na desesperança, mas no pensar que ao perceber o contexto da realidade como um processo em movimento, vê o tempo histórico não como um peso que resulta em algo dado, estático, pronto, mas o vê como uma possibilidade para práxis (FREIRE, 1987).

Ao dialogar sobre o mundo refletimos sobre a educação na qual se valorize os saberes discentes, não para manutenção de um discurso e uma educação fundamentada somente na concepção empírica, mas partindo do real, estabeleça relações intrínsecas e dialógicas com a vida, com aquilo que realmente faz sentido ao educando e educador 
num exercício da práxis conduzindo ao saber científico expressivo e relacionado aos fenômenos naturais observados.

A práxis em Freire se constitui na consciência reflexiva sobre a ação de ensinar, que pressupõe questionamentos que envolvem para quê, o quê, para quem, quando e como ensinar, tendo em vista o contexto educativo político, o currículo, a formação e aperfeiçoamento docente.

Por isso, o professor exerce uma função complexa, na medida em que o ato de estudar para ensinar é difícil, exigindo esforço físico, intelectual, criticidade, curiosidade tanto para planejar o ensino quanto para efetivá-lo na promoção do conhecimento, visto que:

Ensinar é assim a forma que toma o ato de conhecimento que o (a)professor(a) necessariamente faz na busca de saber o que ensina para provocar nos alunos seu ato de conhecimento também.(FREIRE, 1992,p.81)

A práxis se constitui num ato político na qual a ação e reflexão sobre o ensino, se transforma num ato criativo, crítico, não mecanicista sendo o fundamento do ensinaraprender. (FREIRE, 1992). Por isso, num ato político de ensino, a ação e a reflexão colaboram para o dinamismo em sala de aula. Na qualidade de pesquisadoras que adentram o campo numa abordagem participante, nos envolvemos no campo da pesquisa nas dimensões de ensino e aprendizagem que abordaremos a seguir.

\section{A MÚSICA NO ENSINO DE CIÊNCIAS}

Muitas são as possibilidades para a efetivação da práxis pedagógica nos anos iniciais e uma delas são práticas dinâmicas e vinculadas ao real. A sala de aula é um espaço complexo, rico e propício para inúmeras atividades envolvendo observações, questionamentos, experimentos e iniciação científica, visto que:

Aos professores das séries iniciais ou anos iniciais do ensino fundamental é dada a oportunidade, e também a responsabilidade, de introduzir as crianças nos rituais escolares, de apresentar a elas as normas para o convívio neste novo espaço de socialização e de utilizar sua curiosidade natural em relação ao mundo, com a finalidade de seduzi-las para a aprendizagem de fenômenos e processos do mundo. A disponibilidade afetiva do professor, sua capacidade de exerce uma atenta escuta às demandas de cada criança e a força do vínculo que o une a cada um de seus alunos podem ser essenciais 


\section{Ensino, Saúde e Ambiente - V9 (3), pp.64-83, Dez. 2016}

para que a aprendizagem dos conteúdos de ciências seja favorecida (MORAES, 2009, p. 106).

A infância precisa ser vivenciada com desafios e experimentos próximos do real. Não subestimamos os saberes que os alunos trazem, pois esses darão significado para a abstração e apreensão dos novos conceitos.

Com isso, o Ensino de Ciências não pode se resumir na transmissão mecânica das produções científicas, antes se constitui a partir de concepções interpretativas da realidade, já que a Ciência se nutre numa postura de pensamento e ação em relação ao desconhecido (BIZZO, 2009).

Algumas formas dinâmicas que favorecem o ensino por meio da práxis pedagógica é o de associar o Ensino de Ciências com outras áreas do conhecimento utilizando a música em sua linguagem artística como ferramenta de ensino.

A linguagem musical é uma alternativa para muitas aprendizagens, com ela professor e aluno poderão construir muitos saberes inclusive referentes aos conceitos científicos. As disciplinas escolares poderão dialogar com a leitura, escrita, matemática, resolução de problemas, história, geografia, ciências naturais, auxiliando professor e aluno na exploração do mundo natural e social discernindo-o por meio da postura dialética, pois,

a criança está aberta, intuitivamente, a uma enorme variedade de estímulos sonoros, que lhes chegam naturalmente através de "redes", ou seja, de maneira não ordenada, intuitiva e criativa. Cabe ao professor mostrar-se aberto para aceitar o novo, tomando consciência de que é preciso buscar novas maneiras de apreensão do mundo, deixando de lado, critérios enraizados e instituídos; é preciso aceitar de forma natural a energia viva e espontânea das crianças e dos jovens (LOUREIRO, 2003, p.166).

A música "Ora Bolas", do CD Palavra Cantada de PauloTatit e Edith Derdyk é uma possibilidade de trabalho com foco nas Ciências Naturais, na qual a criatividade e dinâmica docente pode construir saberes com alunos dos anos iniciais. Com a música o professor poderá trabalhar várias áreas do conhecimento de forma unânime sem perder as especificidades das disciplinas fomentando o pensar sobre o sujeito no mundo e as possibilidades de transformação. 


\section{APECTOS METODOLÓGICOS}

A pesquisa desenvolvida foi de natureza qualitativa do tipo participante, na qual os sujeitos do ensino, por meio da interpretação e questionamentos coletivos foram valorizados como atores do saber, culminando com novas construções dialógicas e novos conceitos.

Sendo uma pesquisa interpretativa dos fenômenos sociais, a pesquisa qualitativa, também tem caráter descritivo, onde o contato com os sujeitos da pesquisa, permite entender os processos que se desenrolam no dia a dia.

A pesquisa participante tem sua origem numa perspectiva social, onde as integrações e interações coletivas, que, partindo da realidade dos próprios participantes, busca a unidade entre teoria e prática em ações refletidas criticamente, em que todo o processo de construção, coleta de dados, análises e resultados, interferem nas práticas do grupo da pesquisa, promovendo várias e novas investigações que se dirigem à transformação social (BRANDÃO, 2007).

\section{ATIVIDADE DE CAMPO REALIZADA COM ALUNOS DO $3^{\circ}$ DO ENSINO FUNDAMENTAL}

A atividade foi realizada numa escola municipal de Barra Mansa, com alunos do $3^{\circ}$ ano do Ensino Fundamental tendo em vista uma proposta interdisciplinar, cujo objetivo foi trabalhar a música "Ora Bolas" com os alunos, construindo alguns conceitos científicos partir dos conhecimentos cotidianos, promovendo questionamentos e reflexões sobre a Ciência. ${ }^{1}$

O exercício de observar, registrar os progressos e as dificuldades dos alunos, não é apenas uma maneira de colher dados para avaliação da aprendizagem e do trabalho do professor, mas também, uma forma de aprofundar análises fundamentadas em elementos que possam revelar novos significados, alternativas de contemplar o conhecimento escolar (BIZZO, 2009).

\footnotetext{
1 Atividade realizada na disciplina de Debates Conceituais no ensino de Física, solicitada pelo Prf $^{\circ}$ Alexandre Lopes no curso de Pós-Graduação Strictu Senso do PROPEC 
Ensino, Saúde e Ambiente - V9 (3), pp.64-83, Dez. 2016

ORA BOLAS

(Palavra Cantada)

Paulo Tatit e Edith Derdyk

Oi, oi, oi...

Olha aquela bola

A bola pula bem no pé

No pé do menino

Quem é esse menino?

Esse menino é meu vizinho!

Onde ele mora?

Mora lá naquela casa!

Onde está a casa?

A casa tá na rua!

Onde está a rua?

Tá dentro da cidade!

Onde está a cidade?

Do lado da floresta!

Onde é a floresta?

A floresta é no Brasil!

Onde está o Brasil?

Tá na América do Sul

No Continente Americano

Cercado de oceano

E das terras mais distantes

De todo o planeta

E como é o planeta?

O planeta é uma bola que rebola lá no céu

Primeiramente a música foi apresentada aos alunos, por meio de um recurso audiovisual, os alunos cantaram várias vezes para que pudessem aprendê-la. Em seguida, discutimos oralmente, favorecendo assim autonomia discursiva e dialógica para os questionamentos. 
Conversamos sobre as relações entre o ser humano e o mundo, os vizinhos, o espaço político, econômico e social ocupado e modificado pela humanidade, bem como a interação entre a bola no pé do menino e Terra no espaço, contribuindo para que os alunos adquiram novos conceitos, na medida que:

\begin{abstract}
"Se a intenção é que os alunos se apropriem do conhecimento científico e desenvolvam uma autonomia no pensar e no agir, é importante conceber a relação de ensino e aprendizagem como uma relação entre sujeitos, em que cada um, a seu modo e com determinado papel, está envolvido na construção de uma compreensão dos fenômenos naturais e suas transformações, na formação de atitudes e valores humanos" (BRASIL, 1997, p. 33).
\end{abstract}

$\mathrm{Na}$ relação entre os sujeitos, a professora pesquisadora instigou a curiosidade sobre a questão do movimento da bola no pé do menino que vai e volta, perguntando aos alunos por que a bola sempre volta ao pé do menino?

Alguns alunos responderam da seguinte forma.

Aluno 1: A bola volta ao pé do menino pois tudo cai na Terra.

Aluno 2: Tem uma força que atrai as coisas ao chão.

A partir destas respostas podemos observar os conhecimentos empíricos que os alunos têm sobre a relação entre os objetos e a Terra, quando concluíram que a bola quando é arremessada ao alto, tende a voltar ao chão.

A professora pesquisadora pergunta novamente. E por que a música diz que " o planeta é uma bola que rebola lá no céu?

Resposta do aluno 3: Porque ela é leve e o vapor do vento deixa ela ir. Aluno 4 responde ao aluno 3: Não, a Terra é pesada e grande. Olha o tanto de casa, estrada. Ela não é leve, não.

Aluno 5: Tem alguma coisa que faz a Terra flutuar.

Nestes questionamentos, analisamos os caminhos de indagações, os caminhos que os alunos foram construindo sobre o movimento exercido pela interação da Terra atraindo seus corpos para o centro do planeta. A bola relacionada ao Planeta Terra em sua órbita do Sol, que de acordo com a linguagem literária do texto, flutua no espaço que é a gravidade ${ }^{2}$.

Nesse processo interativo de práxis educativa, a professora e os alunos debateram questões cotidianas da física, sem intenções de resultados e comprovações

\footnotetext{
${ }^{2}$ Quando deixamos um objeto cair, ele segue a orientação de todos os outros, o chão. Mas por que isso acontece? Isso ocorre em razão de uma força de atração existente no planeta Terra, chamado de força da gravidade. Ela é responsável por todas as coisas estarem na superfície, inclusive nós.Disponível em:<http://www.escolakids.com/a-forca-de-atracao-da-gravidade.html>. Acesso em ABR/2015 


\section{Ensino, Saúde e Ambiente - V9 (3), pp.64-83, Dez. 2016}

científicos lineares. O movimento do menino de jogar a bola para o alto e ela voltar ao pé do mesmo, é um conceito que poderá ser desenvolvido de forma dinâmica e interpretativa com alunos dos anos iniciais.

A mediação docente neste momento de indagações, dúvidas e diálogos foi fundamental para que o conceito científico de interação entre a bola no pé do menino e o Planeta Terra "rebolando" no espaço se concretizasse, na medida em que os alunos foram construindo hipóteses sobre suas ideias.

Quando o aluno 5 disse que deve ter alguma coisa que segura a Terra no espaço, foi uma concepção prévia que demonstrou alguma semelhança com conceitos científicos, que ampliado pela mediação docente, colabora para a pesquisa reflexiva, coletiva e individual com problematizações significativas.

A ideias dos alunos foram estudadas e mediadas pela professora durante a ensino, e, as interrogações foram convites ao exercício do pensar sobre os movimentos da Terra no espaço.

Vale lembrar que esta atividade poderá ser trabalhada desde o $1^{\circ}$ até o $5^{\circ}$ ano do Ensino Fundamental, desde que respeitadas as peculiaridades de cada ano escolar, incluindo assim diálogos menos ou mais complexos em relação à proposta de trabalho.

Respeitar a singularidade infantil compreende entender que o educador:

\footnotetext{
Não é um cientista, pois seu objetivo não é conhecer o ser humano, mas agir e formar, no contexto específico de uma situação contingente, seres humanos concretos, indivíduos. Ora, esses indivíduos não são a simples expressão da definição científica de ser humano, de sua essência genérica; eles representam, em cada caso, seres particulares, dotados de potencialidades específicas. O educador também não é um técnico nem um artista, no sentido moderno destes termos: sua ação não é baseada num saber rigoroso[...]de causas e efeitos; também não é uma atividade criadora[...]. Ao contrário, o processo de formação visa aqui "desenvolvimento" de uma forma de vida que tenha em si, sua própria finalidade, noção que engloba a um só tempo, os fins naturais, sociais e individuais do ser humano (TARDIF, 2002, p. 159).
}

Essa complexidade que envolve o ensino justifica-se na medida em que haja conscientização de que esse tempo abrangente se processa no espaço escolar, pois é um espaço carregado de singularidades. 


\section{Ensino, Saúde e Ambiente - V9 (3), pp.64-83, Dez. 2016}

Com esta atividade de indagações e problematizações dialógicas, novos conceitos foram apreendidos sobre a gravidade pelos alunos, pois [...] "Newton entendeu que não existe uma gravidade "terrestre" e a gravidade "celeste", mas uma única gravidade [...] tão comum na natureza (BIZZO, 2009, p. 84).

Trabalhamos então, não somente concepções iniciais da gravidade, mas também discutimos sobre as relações interativas entre os objetos e a Terra e a Terra em relação ao Sol e Lua.

Nestes momentos discursivos um outro aluno, denominaremos de aluno 6, falou que: “A interação é como se fosse um ímã, quando colocamos eles ao contrário, eles fazem força e não se encontram, é assim que a Terra fica em relação ao Sol, não é? "

Investigações como essa, proporcionou em situações de sala de aula, momentos de escutas, pois saber ouvir o outro é uma atitude de um fazer democrático de valorização dos saberes discentes, melhoria na qualidade do ensino, debates sobre as hipóteses dos alunos e aprendizagens expressivas, pois,

Se, na verdade, o sonho que nos anima é democrático e solidário, não é falando aos outros, de cima para baixo, sobretudo, como se fôssemos os portadores da verdade a ser transmitida aos demais, que aprendemos a escutar, mas é escutando que aprendemos a falar com eles. Somente quem escuta criticamente o outro, fala com ele (FREIRE, 1996, p. 113).

Momentos como esse de escutas, inquietações e discussões, desencadeiam reflexões que a concepção progressista de educação se compromete, na medida em que o ensino não se traduz na transferência de saberes, mas na elaboração de momentos coletivos de construções e reconstruções de conhecimentos.

\section{ESTUDANDO AS ESTAÇÕES DO ANO}

As estações do ano são ciclos que se repetem todo ano e determinam muitas situações na vida dos seres vivos da Terra. Faz importante estudar sobre os movimentos da Terra ao redor do Sol para ensinarmos sobre os movimentos, os dias, as noites e os anos.

A práxis docente proporcionará meios aos professores de pensarem nas possibilidades e estratégias para o ensino desse conteúdo, pois em se tratando dos movimentos dos planetas na órbita do Sol podemos refletir sobre a Inclinação da Terra em volta do seu eixo e em torno do Sol. 


\section{Ensino, Saúde e Ambiente - V9 (3), pp.64-83, Dez. 2016}

Importante levar em consideração que por meio das estações do ano pode-se trabalhar um projeto pedagógico em que os vários saberes do cotidiano podem ser ampliados e até mesmo compreendidos os conceitos científicos.

Para Gramsci, o senso comum possui até um bom senso, porém é necessário alerta sobre a possibilidade de superestimar o senso comum pois os horizontes têm seus limites no campo empírico os quais se tornam incoerentes (GRAMSCI, 1977).

Entendemos assim que os alunos têm muitos conhecimentos empíricos apreendidos no dia a dia como observar o céu para ver as estrelas, um eclipse lunar ou solar, visto que,

\footnotetext{
Os povos indígenas brasileiros alicerçam parte de sua vida social aos elementos celestes. Por exemplo, os tupis-guaranis associam a prática da caça com as fases da Lua. Devido ao aumento da luminosidade que ocorre entre a Lua crescente e a Cheia, que torna os animais mais agitados, eles consideram a melhor época para a caça a fase entre a Lua Cheia e a Nova (BIZZO, 2009, p. 62).
}

O professor dos anos iniciais, tem muito que aprender sobre os saberes que serão ministrados nos anos iniciais, pois terá que lidar como diversos conceitos e domínios de assuntos diferenciados da língua portuguesa, de matemática, ciências, história e geografia. Por isso, ele tem a sua frente um vasto campo de conhecimentos que necessitam de estudos, aperfeiçoamento e aprimoramento (BIZZO, 2009).

Mas do que ensinar os alunos a nomear as estações do ano ou simplesmente saber em que mês inicia ou termina o verão, outono, primavera e inverno. É importante compreender que os seres humanos também são influenciados na Terra pelos astros celestes que povoam o universo como a força da lua movimentando as marés, o movimento da Terra exercendo influência sobre as plantações, a contagem do tempo para a gestação e nascimento em épocas passadas, medicação com ervas medicinais para tratar as verminoses e até mesmo nas lendas indígenas, pois:

A vida dos homens e mulheres tem sido marcada pelo papel do Sol no planeta. O ciclo dia e noite, as estações do ano e a necessidade de luz e aquecimento fizeram com que o ser humano sempre se preocupasse em compreender os ciclos solares[...]O movimento aparente do Sol ao longo do ano é conhecido há muito tempo por diversas etnias africanas (BIZZO, 2009, p. 63). 


\title{
Ensino, Saúde e Ambiente - V9 (3), pp.64-83, Dez. 2016
}

Observar o céu, contar estrelas, ver onde o sol nasce ou se põe durante vários dias no ano é uma alternativa para estudar sobre as estações do ano, explicando assim sobre o eixo de inclinação da Terra em relação ao seu plano de órbita durante sua volta ao redor do Sol.

Ampliar o conhecimento do cotidiano para o saber científico é uma das tarefas da mediação docente, que faz parte da cultura escolar, ensinar o saber produzido pela humanidade às gerações mais novas, logo ensinar as estações do ano significa ensinar a pensar sobre o ser humano interagindo, conhecendo e modificando o espaço real onde vive.

\begin{abstract}
A ciência deve ser entendida como um processo, isto é, uma maneira de conhecer o mundo, que não utiliza um único método e não depende de gênios individuais. Ao contrário, baseia-se na dedicação disciplinadas a uma investigação, com registro cuidadoso de dados. Possíveis ensaios, que podem corroborá-los ou refutá-los (MORAES, 2009, p. 11).
\end{abstract}

A partir destes estudos, aproveitamos a chegada do inverno, para trabalharmos as estações do ano com os alunos do $5^{\circ}$ ano do Ensino Fundamental, na escola da pesquisa.

Lemos com as crianças a revista de número 103 Ciência Hoje das Crianças, com título, "Giro das Estações" e discutimos oralmente o texto da revista iniciando com a seguinte pergunta: "Primavera, verão, outono e inverno, você já parou para pensar sobre a mudança das estações do ano?

Diante dessa questão, começamos um diálogo a fim levantarmos hipóteses e análises sobre os conhecimentos intuitivos dos alunos, para serem analisadas metodicamente pela curiosidade epistemológica (FREIRE, 1996).

Estudamos sobre o solstício de inferno e verão, que acontecem nos hemisférios Sul dia 21 de junho iniciando o inverno e no Hemisfério Norte iniciando o verão. Sendo assim temos no dia 21 de junho a noite mais longa do ano e o dia mais curto do ano no Hemisfério Sul e o dia mais longo e a noite mais curta do ano no Hemisfério Norte. E no dia 21 de dezembro há uma inversão no processo, inicia o inverno no Hemisfério Norte, tendo a noite mais longa e o dia mais curto do ano e no Hemisfério Sul, inicia o verão com o dia mais longo e a noite mais curta do ano.

Para realizarmos esta atividade com os alunos do $5^{\circ}$ ano, apresentamos de forma concreta e lúdica, um Globo Terrestre simbolizando o Planeta Terra sobre seu eixo e uma lanterna que representou o Sol, para que os alunos pudessem manusear, observar 
concretamente os movimentos que a Terra faz em torno do seu próprio eixo originando os dias e as noites e o movimento em torno do Sol, formando as estações do ano.

Conversamos com os alunos que a Terra está sempre em movimento, girando em torno de si mesma e em torno do Sol e que o movimento dos astros no céu sempre ajudou o homem a marcar a passagem do tempo (VIEIRA, 2000).

Conversamos também sobre o movimento de rotação da Terra que dura 24 horas correspondendo aos dias e noite e consequentemente e que o movimento de translação é o movimento que a Terra faz em volta do Sol completando um ano que demora 365 dias e 5 horas, 48 minutos e 46 segundos. E esse movimento da Terra acontece de forma inclinada, por isso temos as estações do ano, sendo contrárias nos dois hemisférios.

Conversamos também sobre a organização do calendário, passagem do tempo e depois os alunos apresentaram por meio das representações do Globo Terrestre e Lanterna, para os outros alunos e comunidade escolar, numa exposição que aconteceu na escola.

Importante ressaltar que quando as informações são ensinadas aos alunos apenas com apoio do livro didático, na maioria das vezes, os conceitos de rotação, translação e estações do ano não são apreendidos pois exige um grau maior de abstração para os alunos pequenos que necessitam de trabalhar com material concreto, simulando e realizando experimentações e conclusões.

\section{A LITERATURA INFANTIL, UM PROJETO INTERDISCIPLINAR}

A Literatura Infantil é um caminho de possibilidades para o Ensino de Ciências nos anos iniciais do Ensino Fundamental. Por meio da linguagem literária é possível despertar o prazer em ler diversos tipos de textos que vão dos simples aos complexos, dos literários aos científicos e dos verbais aos não verbais. Mas, para que isso aconteça é necessária a reflexão sobre o fazer docente. Levar o professor a pensar sobre a leitura e fazê-lo entender a importância de se trabalhar com dinamismo e criatividade com práticas inovadoras de leituras tendo em vista o Ensino de Ciências é fundamental.

Por meio da linguagem literária se descobre o mundo do faz de conta infantil, pois com a brincadeira e encantamento realizado através da literatura infantil é possível desenvolver habilidades necessárias para leituras mais técnicas e de divulgação científica. Por isso, incentivar a leitura por meio de práticas lúdicas pode contribuir para o exercício da práxis pedagógica no Ensino de Ciências Naturais, logo a presença e 
formação do professor é fundamental para a ação, visto ser a formação a qual falamos aquela processual do dia a dia escolar.

Um dos princípios para a formação do leitor é a formação do professor leitor, por meio de incentivo e trocas de experiências entre os colegas de profissão, onde um colega poderá colaborar com o outro para a produção de novos conhecimentos a fim de realizar em sala de aula um trabalho que envolve leituras de diversos tipos de materiais escritos ou imagéticos.

Por isso, para ensinar a leitura de textos científicos, é preciso primeiramente ser um leitor de diversos tipos de textos incluindo textos científicos. Depois ser um divulgador desses textos com dinamismo e criatividade para cativar e encantar. Essa é uma tarefa árdua docente que envolve além do ensino e técnica profissional, aspectos pessoais de irão determinar a disposição para encantar, cativar e convencer o outro às leituras, primeiro de mundo e depois da palavra.

Pensar no professor como sujeito do conhecimento que também faz parte do processo de ensino e aprendizagem com suas subjetividades significa entender que o professor trabalhando com seres humanos tem a árdua tarefa de trabalhar com o objeto do saber que é o conhecimento e o objeto do trabalho que são os seres humanos. Sabendo que as relações estabelecidas são humanas, individuais e sociais ao mesmo tempo (TARDIF, 2002).

Assim, pensar na figura do professor com agente de transformação é um desafio a ser enfrentado. Freire aborda muitas questões sobre a condição do professor e do aluno. E neste trabalho propomos também confirmar a participação dos atores sociais do ensino e aprendizagem, colocando professor e aluno como centro do processo.

Uma das formas de se trabalhar com a Literatura Infantil é para o meio de projetos didáticos onde a polivalência docente nesse período de ensino favorece o diálogo entre algumas disciplinas. Como exemplo citaremos um trabalho desenvolvido no campo com professores na qual veremos a seguir:

O trabalho teve o objetivo de promover a formação continuada dos professores em serviço e, assim, partindo de textos literários, cada professor recebeu uma poesia para que ao ler pudesse sugerir aos colegas de trabalho, possibilidades de ensino articulando com outras áreas de ensino.

Por exemplo, foram distribuídas aos professores as seguintes poesias: "Leilão de Jardim”, “Ou Isto ou Aquilo", “A Bailarina”, “O Último Andar” e "Uma Palmada bem Dada”, todas as poesias da autora Cecília Meireles. 
Foi solicitado aos professores que lessem as poesias e em seguida sugerissem atividades que pudessem ser trabalhadas no ensino das disciplinas de forma dialógica e interdisciplinar sem perder a especificidade das disciplinas. Pois a interdisciplinaridade de acordo com Fazenda (2011) compreende “... cinco princípios que subsidiam uma prática docente interdisciplinar: humildade, coerência, espera, respeito e desapego".

Com isso verificamos que a interdisciplinaridade é um processo que se dá no campo da subjetividade humana e que está para além de métodos de técnicas de ensino, a prática interdisciplinar é uma construção histórica que envolve movimentos de buscas e descobertas pois,

é necessário aprendermos nesse processo interdisciplinar a separar as perguntas intelectuais das existenciais. As primeiras conduzem o homem a respostas previsíveis, disciplinares, as segundas transcendem o homem e seus limites conceituais, exigem respostas interdisciplinares (FAZENDA, 2011, p. 26).

A sala de aula dos anos iniciais pode ser um campo de produção de saberes com a utilização de uma proposta interdisciplinar por meio da Literatura Infantil, na medida em que a diversidade e a quantidade de livros que chegam às escolas públicas brasileiras por meio do Ministério da Educação podem contribuir para revitalização de novas práticas de leituras para emancipação.

\begin{abstract}
A ocorrência de um trabalho de natureza interdisciplinar nas pesquisas sobre sala de aula anuncia-nos possibilidades que antes não eram oferecidas. Quando isso acontece, surge a chance de revitalização das instituições e das pessoas que nelas trabalham. O processo interdisciplinar desempenha papel decisivo para dar corpo ao sonho - o de fundar uma obra de educação à luz da sabedoria, da coragem e da humildade (FAZENDA, 2011, p. 27).
\end{abstract}

Com essa possibilidade de fundamento numa educação à luz da sabedoria, coragem e humildade que emerge o trabalho com a Literatura Infantil, não como uma velha prática rotineira de ler para decodificar um texto, mas num projeto interdisciplinar de interação com outras disciplinas e a partir delas promover o despertar para a leitura de mundo e alfabetização científica.

Dessa forma, os professores descreveram sugestões de atividades na qual as poesias de Cecília Meireles poderiam ser trabalhadas de maneira interdisciplinar dialogando com Língua Portuguesa, Matemática, Geografia, História e Ciências Naturais, cuja área vamos analisar de maneira mais detalhada na pesquisa. 
Descreveram também que, na poesia Leilão de jardim de Cecília Meireles o diálogo que o texto literário poderá ter com Ciências Naturais seria o estudo sobre os diferentes tipos de animais a partir do filme "Os Insetos" e em seguida trabalhar o solo, a água, o ciclo da vida e as plantas.

$\mathrm{Na}$ poesia "Ou Isto ou Aquilo" de Cecília Meireles, o diálogo com Ciências Naturais se daria no estudo da água, ar, solo, sistema solar, estações do ano, tempo, dia e noite, cuidados com o meio ambiente, preservação dos pássaros, fases da lua, sistema solar, estrelas, planetas, clima e impactos ambientais.

Na poesia "A Bailarina”, a relação dialógica entre as disciplinas pode acontecer por meio do estudo das fases da vida humana, nascimento, crescimento, maturidade, velhice e morte.

Na poesia "Uma Palmada bem Dada", os professores descreveram que poderiam desenvolver um trabalho interdisciplinar por meio de atividades envolvendo os hábitos de higiene, importância da alimentação, importância de se ter uma hora para as coisas, por exemplo, entender que "banho quente" faz mal além de consumir muita energia elétrica. O estudo dos animais e os órgãos dos sentidos.

Nesse processo de ler, refletir, interagir com colegas de trabalho, pensar no planejamento das ações exercemos no campo de pesquisa o exercício da práxis em que a reflexão crítica sobre a prática se torna uma exigência da relação Teoria/Prática sem a qual a teoria pode ir virando blá-blá-blá e a prática ativismo (FREIRE, 1996.P.22).

A entrada e estada no campo é fundamental para o aprendizado entre colegas, pois os saberes são construídos em interação com nossos pares. Em se tratando dos professores dos anos iniciais, muitos saberes podem ser construídos e reconstruídos por meio do trabalho coletivo, do exercício do pensar.

\section{ANÁLISE E DISCUSSÃo DA PESQUISA}

A análise se deu fundamentada na concepção dialógica do ensino em que professor e aluno, na coletividade, constroem e reconstroem saberes a partir da ação e reflexão no ensino. Para isso, o professor necessita de empenho, aperfeiçoamento didático, leituras diversas para que possa mediar o ensino, iniciando com questionamentos, compreendendo as concepções prévias dos alunos favorecendo o ensino e o exercício do pensar. 
As categorias de análise foram organizadas para estabelecer critérios, ideias e concepções acerca de conceitos que dialogam entre si (MINAYIO, 2001). Logo as categorias foram: a importância da concepção dialógica para efetivação do ensino e como as indagações sobre as concepções prévias dos alunos contribuem para o aprendizado.

\section{IMPORTÂNCIA DAS INTERAÇÕES DIALÓGICAS PARA CONSTRUÇÃO DE CONHECIMENTOS}

Entendendo que ensinar não é transferir conhecimento, o professor ao entrar em sala, necessita estar aberto aos questionamentos, ás indagações, curiosidades dos alunos e inibições, visto que ensinar não é transferir conhecimento, mas construí-lo a partir das referências que se tem e a partir das observações que se faz acerca do que se vê e pensa (FREIRE, 2009).

Nas atividades realizadas com a música "Ora Bolas", nas sugestões de práticas com a literatura infantil, ouvindo relatos dos professores nas interações dialógicas, no estudo e indagações sobre as estações do ano, presenciamos as construções de saberes a partir de uma proposta de educação onde os sujeitos interagiram para entendimento da gravidade, solstícios e interdisciplinaridade.

Estes conceitos que foram trabalhados, construídos e reconstruídos a partir de indagações, permitiram não somente o ensino de conceitos que envolvem a gravidade, as estações do ano, solstício e equinócio, interdisciplinaridade, mas também que o ser humano a partir de observações na natureza, no céu, no dia a dia foi criando e organizando e reorganizando o conhecimento com diversas linguagens as quais precisam ser estudadas na escola, respeitando os níveis dos educandos.

\section{O CONHECIMENTO PRÉVIO DOS ALUNOS AUXILIAM NO PROCESSO ENSINO APRENDIZAGEM}

Quando os alunos chegam nos anos iniciais, já apresentam em seus discursos, ações e representações de ideias sobre vários processos e fenômenos naturais como luz, sombra, astros celestes, ideia sobre animais e seu habitat, plantas, o corpo, os sentidos e elas vão organizando essas ideias de acordo com suas vivências.

Assim, o conhecimento prévio que os alunos têm com relação a si, a natureza, as concepções de aprendizagem e saberes é fundamental para que o professor possa compreender como e por onde começar o ensino. As crianças já têm uma vasta bagagem 
de conhecimentos intuitivos que por meio das interações e levantamento de hipóteses, muitos conceitos e concepções são estudadas, ampliadas e ou reconstruídas nas linguagens próprias de cada ciência.

$\mathrm{Na}$ proposta de atividade da música "Ora Bolas", observamos que os alunos construíram várias respostas sobre a questão da bola voltar ao pé do menino em sua relação com ao chão, bem como a relação da Terra flutuar no espaço em interação com o Sol e a Lua.

Embora a maioria dos alunos não souberam o nome gravidade, um aluno com suas concepções prévias disse que existe alguma coisa que faz a Terra flutuar.

São nesses momentos de interações dialógicas que o professor em sua práxis, lançará mão de conceitos mais complexos para que o aluno também construa significados a partir daquilo que já tem alguma ideia.

Com a pesquisa, percebemos que, as estações do ano, são ciclos conhecido pelos alunos, porém a inclinação da Terra em volta de um eixo imaginário, sua interação entre Sol e Lua e suas interferências na vida na Terra como contagem do tempo, auxílio no plantio e colheita são conceitos importantes que precisam ser incluídos no ensino para ampliação dos saberes e conhecimento que vários povos da antiguidade já estudavam o céu e contavam o tempo a partir dos ciclos celestes.

\section{CONCLUSÃO}

Embora encontremos muitos desafios para a práxis pedagógica no ensino de Ciências nos anos iniciais do Ensino Fundamental, existem muitas possibilidades que poderão nortear o trabalho docente por meio do trabalho com músicas, projetos interdisciplinares, articulação com a literatura infantil, entre outros.

Essas são algumas possibilidades que contribuirão para o entendimento do mundo a partir do ambiente local e global, com observações e reflexões sobre o ser humano e suas relações com a sociedade e tecnologia.

Conhecer os astros no céu, as estações do ano, os solstícios, representar a Terra em relação ao Sol, entendendo a origem do dia e da noite, os meses do ano, foi fundamental para o ensino de Ciências na pesquisa, visto que com desafios e indagações a construção de conceitos científicos foram alcançados, pois os alunos apreendam conceitos da gravidade e da vida na Terra, conceitos de contagem do tempo a partir dos astros celestes entre outros. 
As concepções prévias dos alunos e as indagações nas aulas mediadas pelo professor contribuíram para que o ensino envolvendo as Ciências Naturais, fosse dinâmico e integrasse o processo de ação e reflexão.

\section{REFERÊNCIAS:}

BIZZO, N. Ciências, Fácil ou difícil? Nélio Bizzo 1ª ed. São Paulo: Bituta, 2009.

N. Mais Ciências no Ensino Fundamental: metodologia de ensino em

foco/Nélio Bizzo.- São Paulo: Editora do Brasil, 2009.

Brandẽo, C. R.; BORgeS, M. C. A Pesquisa Participante.Rev. Ed. Popular, Uberlândia, v. 6, p.51-62. jan./dez. 2007. Disponível em: <http://www.seer.ufu.br/ index.php/reveducpop/article/view/19988/10662>. Acesso em: 27 jul. 2016

FAZENDA, I. C. A. Integração e Interdisciplinaridade no Ensino Brasileiro Efetividade ou Ideologia. São Paulo, 6ª ed. 2011.

FREIRE, P. Pedagogia do Oprimido, 17ª ed. Rio de Janeiro, Paz e Terra, 1987.

Cortez, 1986.

A importância do ato de ler: em três artigos que se completam. São Paulo:

Pedagogia da Autonomia, saberes necessários a prática educativa/Paulo

Freire. São Paulo; Paz e Terra, 1996.

Pedagogia da esperança: um reencontro com a pedagogia do oprimido/

Paulo Freire.- notas: Ana Araújo Freire. Rio de Janeiro: Paz e Terra, 1992.

GRAMSCI, Antônio. Quadernidel Cárcere. Edição Crítica do Instituto Gramsci, org. Valentino Gerratana. Turim: Einaudi, 1977.

MONASTA, A. Antônio GRAMSCI/ Atillio Monasta; tradução: Paolo Nosella. Recife: Fundação Joaquim Nabuco, Editora Massangana, 2010. 154 p.: il. - (Coleção Educadores)

MORAIS, M. B. Ciências: ensino fundamental/ Coordenação Antônio Carlos Pavão. Brasília: Ministério da Educação, Secretaria de Educação Básica, 2009, 212p. il.

(coleção Explorando o Ensino) v.18.

LOUREIRO, A. M. A. O ensino de música na escola fundamental. Campinas. SP: Papirus, 2003.

MINAYO, M. C. de S. (org.) - Teoria, método e criatividade, $14^{\mathrm{a}}$ ed. MINAYO, Maria Cecília de Souza (org.). Pesquisa Social. Teoria, método e criatividade. 18 ed. Petrópolis: Vozes, 2001

BRASIL. Secretaria de Educação Fundamental. Parâmetros curriculares nacionais: introdução aos parâmetros curriculares nacionais / Secretaria de ISSN 1983-7011 
Ensino, Saúde e Ambiente - V9 (3), pp.64-83, Dez. 2016

Educação Fundamental. - Brasília: MEC/SEF, 1997. 126p. 1. Parâmetros curriculares nacionais. 2. Ensino de primeira à quarta série. I. Título.

TARDIF, M. Saberes docentes e formação profissional. 4ª Ed. Rio de Janeiro: Vozes, 2002.

RUTH. H.T. Astronomia no dia a dia. Revista Ciência Hoje das Crianças. Janeiro. Ed. Bianca Encarnação. no 203, p. 06-09, julho de 2009.

VIEIRA, G. G. O Giro das estações. Revista Ciência Hoje das Crianças. Rio de Janeiro. Ed. Bianca Encarnação.nº 103, p. 20-23, junho de 2000. 